\title{
REFLEXÕES SOBRE OS DIREITOS SOCIAIS * / REFLECTIONS ON SOCIAL RIGHTS
}

\author{
Vicente de Paulo Barretto ${ }^{1}$
}

\begin{abstract}
Resumo
O presente artigo procura estabelecer os parâmetros teóricos dentro dos quais poderemos investigar a fundamentação ética dos direitos sociais, assim como foi extensamente elaborada a fundamentação ética dos direitos civis e políticos no estado liberal de direito.

O paradigma que irá guiar tais reflexões é o paradigma kantiano, que, através da abertura metodológica de suas obras nos permitirá desenvolver a ideia de que os direitos sociais têm caráter de universalidade, isso por serem direitos que se encontram nas origens da sociedade humana, representando a dimensão da pessoa como bios politikòn.
\end{abstract}

Palavras-chave: Fundamentação ética dos direitos sociais. Paradigma kantiano. Universalidade. Bios politikòn.

\begin{abstract}
This article seeks to establish the theoretical parameters within which we can investigate the ethical foundation of social rights, as has been extensively elaborated the ethical justification for civil and political rights at Liberal State of Law.

The paradigm that will guide these reflections is the Kantian paradigm, which, through methodological openness of his works allow us to develop the idea that social rights have mandatory character of universality, that because they are rights that are at the origins of human society, representing the dimension of the person as bios politikòn.
\end{abstract}

Keywords: Ethical foundation of social rights. Kantian paradigm. Universality. Bios politikon.

\section{Um novo paradigma jurídico}

O estado democrático de direito, como estabelece o Preâmbulo da Constituição Brasileira de 1988, destina-se a assegurar "o exercício dos direitos sociais e individuais, a

\footnotetext{
${ }^{1}$ Doutor em Direito. Professor do Mestrado e Doutorado em Direito da UNESA. Professor visitante do PPG em Direito da UNISINOS. E-mail: vpbarreto@terra.com.br.

Agradeço ao trabalho de pesquisa da mestranda Rachel Mathias Soares Pontes, que permitiu a redação deste texto. As opiniões nele desenvolvidas são de minha responsabilidade. ${ }^{1}$
} 
liberdade, a segurança, o bem-estar, o desenvolvimento, a igualdade e a justiça". No art. $6^{\circ}$, a Constituição Federal estabelece quais são esses direitos sociais: a educação, a saúde, o trabalho, a moradia, o lazer, a segurança, a previdência social, a proteção à maternidade $\mathrm{e}$ infância e a assistência aos desamparados. Esses são valores considerados pelo texto constitucional como "valores supremos". Observa-se, entretanto, na doutrina e na jurisprudência, uma profunda e sintomática dificuldade em lidar com a idéia e o regime jurídico dos direitos sociais, que perdem as características de valores supremos da ordem constitucional, consagrados na lei magna ( $\operatorname{arts} .6^{\circ}$ a $11^{\circ}$ ), e pertencentes, assim, à categoria dos direitos fundamentais (Título I da Constituição de 1988). Os direitos sociais terminam, pelas razões que veremos a seguir, rebaixados na hierarquia normativa, reduzidos a simples normas programáticas a espera de serem regulamentadas para produzirem efeitos.

O constituinte ao listar os valores supremos do estado democrático de direito, considerou os direitos sociais como categoria jurídica essencial do regime que pretenderam estabelecer através da Constituição, e, portanto, pertencentes à mesma categoria hierárquica dos direitos civis e políticos. A hipótese a ser desenvolvida neste trabalho é a da que o legislador constituinte, ao assim proceder, refletiu um novo paradigma, onde os direitos sociais tornam-se, nos termos em que se encontram expressos na Constituição, direitos fundamentais que mantêm relações de igualdade com os direitos civis e políticos.

As dificuldades conceituais encontradas na leitura do texto constitucional originamse, provavelmente, na falta de uma fundamentação lógico-racional para os direitos sociais, a fim de que possam ser integrados no núcleo normativo do estado democrático de direito, ao lado dos direitos civis e políticos, consagrados no estado liberal. A exclusão dos direitos sociais reflete, a nosso ver, o predomínio de um tipo de "hermenêutica constitucional" que entra em conflito com o próprio paradigma político e jurídico do estado democrático de direito. Como argumenta com precisão Lênio Streck esse tipo de organização estatal pressupõe para a sua plena realização uma hermenêutica peculiar, que supera a "hermenêutica constitucional" (a técnica própria e específica de interpretar a Constituição) tradicional, diferenciando-se em virtude de ser uma hermenêutica em que a Constituição é vista como "uma ferramenta que 
está à "disposição" do intérprete", sendo na linguagem heideggeriana um modo-de-ser-no mundo do intérprete( Streck, 2002:194-198). Essa a razão pela qual a parte programática do texto constitucional pode ser considerada como tendo, ao lado do seu caráter principiológico, a função de caixa de ferramentas com a qual deverá contar o intérprete para a plena realização dos objetivos últimos do sistema constitucional. Com isto, a parte programática da Constituição torna-se necessariamente impositiva, independente, portanto, de arranjos políticos, sociais ou econômicos.

Bobbio, em conhecida frase, que expressa, afinal de contas, um truísmo, afirmou que “o problema fundamental em relação aos direitos do homem, hoje, não é tanto o de justificálos, mas sim o de protegê-los" (Bobbio, 1992: 24). Não se pode discordar de Bobbio quanto ao desafio que representa a luta pela proteção dos direitos humanos. No entanto, há casos em que a justificação e a fundamentação dos direitos é etapa indispensável e indissociável da sua proteção. A conceituação e o reconhecimento das garantias dos direitos humanos nos diferentes sistemas normativos, nacionais e internacionais, resultaram do seu progressivo amadurecimento histórico. Quando avaliamos a evolução política e legal dos direitos humanos (Marshall,1967:57 e segs.) constata-se que a cidadania democrática contemporânea, além de ser a vinculação jurídica do indivíduo a um estado soberano, compreende também uma série de direitos e exigências morais. Esses direitos civis e políticos, núcleo do estado liberal, foram sendo consagrados nos sistemas jurídicos através de processo histórico específico, onde o momento da sua justificativa e fundamentação tornaram-se etapas integrantes da sua implementação. A proteção de que gozam, na atualidade, os direitos de primeira geração, resultou, assim, de argumentos que aprofundaram a importância da temática dos direitos humanos para a construção do estado liberal de direito.

A tradição liberal, entretanto, que deita as suas raízes no argumento de Locke (Segundo Ensaio sobre o Governo Civil), estabeleceu a questão dos direitos humanos em função, exclusivamente, da propriedade ( Macpherson, 1962). Para Locke e os ideólogos do estado liberal, o cerne dos direitos civis e políticos encontrava-se no direito de propriedade, que iria sedimentar, proteger e assegurar o produto do exercício da autonomia, da liberdade e do trabalho humano. Essa a razão pela qual o sistema político e jurídico do estado liberal organizaram-se em função e para a garantia do exercício das liberdades e das igualdades de 
uma sociedade de proprietários. Processo semelhante ao constatado na construção do estado liberal, ocorre nos estágios de consagração ética, política e constitucional dos direitos sociais, nascidos e afirmados através de um processo de legitimação e efetividade crescentes no âmbito da própria transformação doestado liberal em direção ao estado democrático de direito.

$\mathrm{O}$ argumento que pretendo desenvolver parte de um pressuposto radical, qual seja o de que os direitos sociais não são meios de reparar situações injustas, nem são subsidiários de outros direitos. Não se encontram, portanto, em situação hierarquicamente inferior aos direitos civis e políticos. Os direitos sociais - entendidos como igualdade material e exercício da liberdade real - exercem no novo paradigma, aqui proposto, posição e função, que incorpora aos direitos humanos uma dimensão necessariamente social, retirando-lhes o caráter de "caridade" ou "doação gratuita", e atribuindo-lhes o caráter de exigência moral como condição da sua normatividade. Constituem-se, assim, em direitos impostergáveis na concretização dos objetivos últimos pretendidos pelo texto constitucional.

O direito do estado liberal concebido no contexto do contratualismo e centrado na propriedade, fechou-se no chamado império da lei e no formalismo jurídico abstrato, impedindo a consideração dos direitos sociais como direitos humanos. Os direitos sociais, como direitos nascidos, precisamente, em virtude e como resposta à desigualdade social e econômica da sociedade liberal, constituem-se como núcleo normativo central do estado democrático de direito. Mas o seu aparecimento provocou um entendimento preliminar de que ameaçariam a propriedade e o contrato. Neste sentido, Weber aponta para a disfunção encontrada na sociedade liberal, que se expressa no conflito entre a legalidade material e a pessoa concreta, de um lado, face o formalismo e "a fria "objetividade" normativa do governo burocrático". Concluí Weber, afirmando que a solução desse conflito cabe ao direito e ao governo que para isto devem estar a serviço "da nivelação das possibilidades da vida econômica e social face aos possuidores, e somente podem desempenhar esta função, quando assumem um caráter não formal, ou seja, um caráter substancialmente ético" (grifo meu) (Weber, 1944:735).

Processa-se, assim, uma revolução copernicana no paradigma jurídico 
contemporâneo no que se refere ao conteúdo dos próprios direitos fundamentais clássicos. Esses direitos, consagrados e garantidos no estado liberal, ao perderem o seu caráter meramente formal, que visava a regulação de conflitos entre proprietários, ganham no contexto do estado democrático de direito, novos conteúdos e materializam-se sob a forma de liberdades e igualdades reais. Esse novo paradigma necessita ser justificado racionalmente para que possa ser aplicado "eticamente", como previa Weber. Somente então teria sentido responder às quatro questões básicas, sistematizadas por Sarlet: em que medida os direitos a prestações, em virtude do disposto no art. $5^{\circ}, \S 1^{\circ}$ da Constituição Federal, são diretamente aplicáveis; quais os efeitos jurídicos inerentes à eficácia jurídiconormativa dos direitos sociais; esses direitos expressam um direito subjetivo individual à prestação? E, finalmente, como poderá ser reconhecido ( Sarlet, 2001: 258).

\section{A efetividade dos direitos sociais}

Consagrados na Declaração Universal dos Direitos Humanos (art. 22), considerados por alguns autores como fórmula fraca e vazia de efetividade (Cortina,1998:86) e nos textos constitucionais da maioria dos Estados, os direitos sociais integram os ordenamentos jurídicos sob a regência dos quais vive a maior parte da população do planeta. Todavia, no que diz respeito à prática social e política, poucos são os Estados que protegem ampla e universalmente os direitos sociais. Histórica e teoricamente tem-se justificado a baixa efetividade dos direitos sociais afirmando-se que não existe a indivisibilidade dos direitos humanos, pois na prática histórica e nos dispositivos legais, encontram-se diferentes níveis de direitos, sendo que os direitos humanos reconhecidos como direitos fundamentais nos textos constitucionais seriam unicamente os direitos civis e políticos. Em conseqüência, estabelecem-se duas "categorias" de direitos humanos, rompendo-se a unidade integradora do bloco sistêmico dos direitos humanos (direitos civis-sociais) como se encontra determinado no texto constitucional. O texto constitucional resultou, entretanto, da afirmação extensiva dos direitos humanos, neles incluindo-se os direitos sociais, sendo essa a razão da recuperação na teoria dos direitos humanos do significado lógico e estrutural dos direitos sociais, como pretendem as recomendações da Conferência de Viena de 1993.

Existem diferentes formas de argumentação que sustentam a inconsistência dos direitos sociais como direitos humanos fundamentais, vale dizer, afirmados universalmente e 
consagrados no sistema jurídico nacional. Todas partem do pressuposto de que os direitos fundamentais sociais não são reconhecidos "como verdadeiros direitos" (Krell, 2002:23). Uma das formas mais comuns de se negar efetividade aos direitos sociais é retirar-lhes a característica de direitos fundamentais. Afastados da esfera dos direitos fundamentais, ficam privados da aplicabilidade imediata, excluídos da garantia das cláusulas pétreas, e se tornam assim meras pautas programáticas, submetidas à "reserva do possível” ou restritos à objetivação de um "padrão mínimo social”. A doutrina jurídica contemporânea oscila entre esses dois pólos argumentativos, servindo, a nosso ver, para justificar modelos políticos e sociais que se antepõem à idéia central do estado democrático de direito, que afirma ser a observância dos direitos sociais uma exigência ética, não sujeita a negociações políticas (Campilongo, 1995:135).

Os valores humanos da liberdade, igualdade e da dignidade da pessoa humana, dos quais os direitos sociais serão uma forma de manifestação, impõem-se, progressivamente, no contexto do modelo liberal, onde se torna determinante na produção e na aplicação da lei o valor econômico da melhor relação custo-benefício para o investimento do capital. Esses valores refletem a própria natureza da sociedade democrática, que considera o social como envolvendo todo o conjunto das relações humanas. Esse entendimento da natureza da sociedade tem sido tema recorrente no pensamento social, desde as suas primeiras formulações, na Grécia Antiga, por Aristóteles (Ética a Nicômaco, 1097 b, 10) e que encontra no texto de Marshall (1967:87-107) a sua sistematização: a dimensão social abarca toda a sociedade, desde o direito à segurança até o mínimo de bem-estar econômico, materializa-se através da divisão da herança social, implicando na subordinação do preço de mercado à justiça social, na substituição da livre negociação por uma declaração de direitos. Essa idéia de considerar a declaração de direitos como o instrumento próprio para a regulação das relações sociais na economia de mercado, aponta para uma solução jurídica integradora dos aspectos éticos e sociais da sociedade democrática, pois atribui ao social, esfera específica de manifestação da liberdade, a última palavra na intervenção do poder público com vistas à correção de desigualdades sociais.

3. Falácias teóricas sobre os direitos sociais

A integração dos direitos sociais no quadro dos direitos humanos implica 
logicamente em considerá-los, preliminarmente, sob a perspectiva da sua universalidade. O núcleo do argumento central, que não incluí na categoria dos direitos humanos os direitos sociais, refere-se à sua universalidade. Argumentos teóricos e práticas, políticas e legislativas, contestam essa universalidade, separando os direitos sociais dos direitos civis e políticos. A hipótese a ser desenvolvida neste trabalho é a de que esses argumentos somente poderão ser superados se e quando situarmos os direitos sociais numa dimensão propriamente ética o que lhes trará, assim como trouxe, historicamente, para os direitos civis e políticos, a qualidade de direitos humanos universais. Torna-se, assim, necessário analisar os fundamentos lógicos e empíricos dos direitos sociais para que se possa verificar onde se situam os obstáculos a sua integração no corpo dos direitos humanos. Trata-se de construir um novo paradigma, que justifique racionalmente a integridade dos direitos humanos, neles incluídos os direitos sociais.

$\mathrm{O}$ argumento mais difundido contra a natureza de direitos humanos dos direitos sociais refere-se à sua efetividade, pois os direitos sociais diferenciar-se-iam dos direitos civis e políticos pelo fato de terem caráter programático. Os textos constitucionais ao proclamarem e regularem os direitos sociais estabeleceriam normas de caráter programático, dependentes de regulação infraconstitucional posterior e, por essa razão, esses direitos não teriam a força de direitos públicos subjetivos. Seriam tão-somente direitos públicos negativos, mas que de qualquer forma tornariam inconstitucional qualquer medida do Poder Público tendente a retroceder em matéria de direitos sociais.

Ocorre, porém, que nem mesmo esse aspecto de orientação negativa, oriundo de uma interpretação menos consistente do significado dos direitos fundamentais sociais, tem sido observado na realidade brasileira. A grande maioria dos direitos sociais previstos na Carta de 1988 encontra-se aguardando regulamentação sendo mesmo considerada por doutrinadores e magistrados como não obrigando ao seu cumprimento, seja sob a forma de implementação de serviços públicos, seja na salvaguarda de direitos adquiridos, como os da previdência. $\mathrm{O}$ detalhamento constitucional dos direitos sociais passa a servir de mero adorno ao arranjo político que termina pôr preservar as desigualdades sociais que a própria Constituição pretende corrigir.

Tendo como pano de fundo essa rejeição política da obrigatoriedade dos direitos 
sociais, construiu-se no âmbito da teoria três tipos de falácias, que sustentam a exclusão dos direitos sociais da categoria dos direitos humanos fundamentais. Essas falácias ocorrem em três tipos de questões: no âmbito do conflito dos direitos, na concepção funcional dos direitos sociais e nas questões suscitadas pela aplicação do formalismo positivista na interpretação dos direitos fundamentais:

a) O primeiro problema enfrentado pela doutrina no que se refere à exclusão dos direitos sociais da pauta dos direitos humanos reside no possível conflito latente com os direitos civis e políticos. Os direitos sociais seriam considerados como referidos a dimensões não-substanciais da sociedade, pois seriam direitos que, para serem implementados - se isto fosse possível em virtude das limitações orçamentárias, argumenta a doutrina alemã da "reserva do possível" -, violentariam os direitos constitutivos do núcleo do estado liberal: as liberdades individuais e a propriedade. Como escreve Krell (2002:47), essa posição doutrinária nasceu de circunstâncias históricas específicas, quando o populismo igualitarista e coletivista do estado social-nazista, levou à supressão das conquistas do estado liberal. Em conseqüência, a doutrina do estado e o sistema político da Alemanha pós-Segunda Guerra Mundial - estabelecido na Constituição da República Federativa da Alemanha de 1949 - tiveram a preocupação de evitar a todo o custo que se repetissem as condições sociais e econômicas que serviram de caldo de cultura para o surgimento de projetos políticos, como o nazismo, que, em nome da correção da crise social, provocou o sacrifício das liberdades públicas e individuais da nação alemã;

b) A segunda dificuldade teórica com que se defronta uma justificativa dos direitos sociais como direitos humanos, reside na concepção funcional dos direitos sociais. Por concepção funcional, entenda-se aquela que atribui aos direitos sociais uma funcionalidade reparadora, situando-os face aos direitos civis e políticos numa relação de subsidiariedade (Martinez de Bringas, 2001). Nessa linha de argumentação, os direitos sociais seriam direitos de segunda ordem a serem, eventualmente, respeitados, não 
porque tenham a mesma natureza dos direitos fundamentais constitutivos da personalidade humana, mas por

responderem a demandas sociais e econômicas conjunturais. Essa vertente teórica derivada da teoria da "reserva do possível", parte da mesma premissa falaciosa, qual seja, a de que existe uma impossibilidade objetiva na implementação dos direitos sociais. A teoria do "mínimo social" procura, em outras palavras, minimizar a radicalidade da teoria da "reserva do possível", ao sustentar, nas palavras do seu mais insigne formulador na cultura jurídica brasileira, que a pessoa sem o mínimo necessário à existência perderia a condição inicial da liberdade que é a sobrevivência (Torres, 1999: 262). Ainda que Torres introduza no debate sobre o tema uma dimensão moral , qual seja, a vinculação do exercício da liberdade, valor superior no estado constitucional liberal, à questão da sobrevivência, permanece sem resposta a indagação sobre em que medida o valor da liberdade realiza-se através de condições sociais específicas. E essas condições referem-se, precisamente, à garantia de direitos sociais considerados como a materialização da liberdade;

c) Outra dificuldade de caráter teórico encontra-se na concepção do formalismo positivista, que entende o direito como um sistema de normas, onde o império da liberdade formal torna-se o princípio hegemônico na aplicação da lei. Essa concepção, preponderante na

cultura jurídica brasileira, parte da ignorância dos conteúdos do direito, como se o exercício das liberdades pudesse ocorrer no espaço abstrato das regulações legais e não no contexto das relações de poder encontradas na realidade social objetiva. Isto porque é neste contexto que se realiza a autonomia do ser humano, onde se concretizam os direitos proclamados no texto constitucional, podendo-se, então, através do sistema jurídico, corrigir-se as situações sociais impeditivas da implementação das liberdades individuais. 
Os três problemas acima referidos mostram faces de uma mesma idéia, difundida na cultura jurídica contemporânea. Essa idéia encontra a sua formulação no argumento neoliberal de que os direitos sociais não passam de promessas vazias e que, em última análise, acabam sendo atentatórios às liberdades e direitos individuais. Sustenta-se, inclusive, nesta linha de argumentação, que muitas das normas constitucionais sobre direitos sociais, por não possuírem um mínimo de condições para a sua efetivação, acabam servindo como álibi para criar a imagem de um Estado que responde normativamente aos problemas reais da sociedade (Barroso, 1996:61). Há aqueles que atribuem uma função preponderantemente ideológica para os direitos sociais, que constituiriam uma forma de manipulação ou de ilusão, que imuniza o sistema político contra outras alternativas (Krell:2000;13). O mesmo autor chama a atenção para o fato de que o exercício dessa função ideológica não é necessariamente nocivo, desde que não se paralise por completo a implementação dos direitos sociais garantidos na Constituição. A função ideológica positiva dos direitos fundamentais sociais programáticos da Carta de 1988 residiria em seu papel de referência, atuando como um ideal que pudesse contribuir para a transformação progressiva do sistema social.

Essa idéia difusa sobre a natureza dos direitos sociais repercute no processo judicial, onde grande parte da magistratura brasileira emprega formas de interpretação constitucional, calcadas no formalismo jurídico positivista, corrente teórica predominante na formação de gerações de profissionais do direito. Resiste, assim, no quadro do estado democrático de direito, um modelo formal de argumentação em segmentos representativos da doutrina e da jurisprudência no Brasil, que não permite a integração de pontos de vista valorativos, ligados à justiça material no processo judicial, o que representa, em última análise ignorar a exigência estabelecida no próprio Preâmbulo da Constituição de 1988.

4. Falácias políticas sobre os direitos humanos e sociais

As falácias mais usuais argüidas contra a natureza de direitos humanos dos direitos sociais deitam suas raízes no fato de que esses direitos sociais encontram-se no estágio de sua justificativa e fundamentação, e, por essa razão, recebem fortes críticas relativas à possibilidade de sua implementação no estado democrático de direito. A hipótese que pretendemos examinar é a de que as falácias políticas utilizadas para, junto com as teóricas, 
excluir os direitos sociais do âmbito dos direitos humanos fundamentais, evidenciam somente relações sociais e econômicas específicas, centradas na propriedade e na economia de mercado livre, e não social. Algumas constatações empíricas mostram como, por detrás dos argumentos teóricos, escondem-se posições ideológicas e políticas que necessitam serem explicitadas. Essas falácias políticas assumem a forma de três argumentos principais, que procuram justificar a exclusão dos direitos sociais da categoria dos direitos humanos fundamentais.

$1^{\mathrm{o}}$ argumento - os direitos sociais são direitos de segunda ordem

Essa falácia político-ideológica sustenta que os direitos sociais são categorias jurídicas de segunda ordem, pois não participam do momento fundador do estado de direito, que foi estruturado em função e para assegurar, preliminarmente, os direitos civis e políticos. $\mathrm{O}$ estado de direito, na primeira fase do liberalismo, estruturou-se em função de agentes políticos privilegiados - os proprietários- com vistas a regular os conflitos em torno de núcleos de direitos, chamados de civis, porque visavam assegurar aos cidadãos, aqueles que por lei participavam do sistema político, social e econômico, um conjunto de direitos e garantias individuais. A passagem do estado liberal para o estado democrático de direito fezse pela extensão dos direitos civis e políticos( principalmente o direito de votar e ser votado) a um número crescente de cidadãos, que através da representação política e dos movimentos sociais, alteraram substantivamente o sistema jurídico do estado liberal clássico. Neste processo político, social e legislativo de democratização do estado liberal de direito o seu fator determinante foi a incorporação dos direitos sociais ao corpo dos direitos humanos fundamentais; na verdade, a salvaguarda desses direitos civis e políticos,

originários do estado liberal clássico, passou no contexto do estado democrático de direito a pressupor a realização dos direitos sociais. Estabeleceu-se, portanto, ao contrário do que afirma a falácia examinada, uma relação de reciprocidade e integração entre dois tipos de categorias dos direitos fundamentais.

Os direitos sociais, portanto, não são categorias jurídicas de segunda ordem, pois a própria natureza dos direitos civis, pressupõe a sua corporificação através desses direitos 
sociais. Essa relação torna-se ainda mais evidente quando constatamos que a plena realização dos objetivos da sociedade democrática de direito, como estabelecidos no texto constitucional, tem com seu fundamento dois instrumentos político-institucionais, os direitos civis e políticos, pôr um lado, e os direitos sociais, pôr outro. Para tanto, os direitos sociais - entendidos como igualdade material e liberdade real - constituem uma fonte substantiva, não formal ou adjetiva, dos direitos fundamentais. E essa característica faz com que os direitos fundamentais no quadro do estado democrático de direito sejam tais na medida em que assegurem e estabeleçam direitos sociais.

Tendem, portanto, a convergir, os dois princípios básicos do estado liberal, até então considerados como autônomos e independentes: o princípio da liberdade e o da igualdade, sendo o primeiro, na teoria liberal clássica, considerado hegemônico em relação ao segundo. Transitamos então para um novo patamar conceitual, onde os direitos sociais irão representar a integração dos princípios da igualdade material e da liberdade real, que não é aquela meramente proclamada nos textos legais. Os direitos sociais adquirem um novo papel no sistema jurídico, deixando de ser simples expedientes funcionais, destinados a compensar situações de desigualdade, e passando a atuar como núcleos integradores e legitimadores do bem comum, pois será através deles que se poderá garantir a segurança, a liberdade, a sustentação e a continuidade da sociedade humana.

$2^{\circ}$ argumento - os direitos sociais dependem de uma economia forte

Outra falácia, usualmente argüida em favor da exclusão dos direitos sociais da categoria de direitos fundamentais, consiste em sustentar-se que a efetividade dos direitos sociais depende da existência de uma econômica forte, onde as cifras de manutenção das prestações sociais poderiam ser suportadas. Esse argumento simplifica a complexidade do sistema econômico e social da modernidade, pois parte do pressuposto de que somente os países ricos teriam condições de sustentar políticas sociais consistentes e que atendessem aos ideais de justiça social. Isto porque a presença do poder público na implementação dos direitos sociais independe de mais ou menos recursos públicos, mas encontra-se diretamente ligada à função principal do Estado na sociedade moderna, qual seja, assegurar o bem comum. A alocação de recursos para suprir demandas sociais depende, em última instância, da vontade política que se expressa no estado democrático de direito através do 
sistema representativo, quando ocorre a escolha pelo eleitor dos projetos público de sua preferência. Tanto a questão da liberdade, como a da igualdade, constituem o pano de fundo diante do qual serão escolhidas as alternativas de políticas públicas apresentadas pelos partidos políticos. A sociedade é que deverá escolher quais as opções político-econômicas e, portanto, em quais setores serão aplicados preferencialmente os recursos públicos.

Por outro lado, esse argumento não se refere ao fato de que, mesmo nas economias fortes, continua-se a advogar a exclusão dos direitos sociais da categoria dos direitos fundamentais. Como sustenta Martinez de Bringas (2001), a persistência da exclusão social nas economias mais fortes do planeta expressa uma crença enraizada em setores do pensamento social e político de que é uma fatalidade histórica a existência das desigualdades sociais, pois estas têm a ver com a própria natureza da sociedade humana. Esse argumento tem como eixo principal a crença ideológica de que é impossível a consideração aprioristica da realidade social a ser caracterizado como um espaço de "ausências de carências".

$3^{\circ}$ argumento- o custo dos direitos sociais supera os recursos orçamentários

Outro argumento falacioso refere-se ao custo dos direitos sociais. Chamada, também, da falácia da "reserva do possível" representa um argumento preponderante no projeto neoliberal contemporâneo. Vestida de uma ilusória racionalidade, que caracteriza a "reserva do possível" como o limite fáctico à efetivação dos direitos sociais prestacionais, esse argumento ignora em que medida o custo é consubstancial a todos os direitos fundamentais. Não podemos nos esquecer do alto custo do aparelho estatal administrativojudicial necessário para garantir os direitos civis e políticos. Portanto, a escassez de recursos como argumento para a não observância dos direitos sociais acaba afetando, precisamente em virtude da integridade dos direitos humanos, tanto os direitos civis e

políticos, como os direitos sociais.

Estabelecer uma relação de continuidade entre a escassez de recursos públicos e a afirmação de direitos acaba resultando em ameaça à existência de todos os direitos. Supõe, além do mais, que o sistema jurídico serviria para solucionar conflitos em situação ideal de igualdade absoluta, onde não houvessem carências e situações sociais de necessidade, 
funcionando o direito no quadro de relações contratuais, sinalagmáticas, entre agentes sociais com os mesmos poderes. O não reconhecimento dessa situação de desigualdade no direito liberal é que permite que se argua como os direitos sociais encontram-se fora do sistema de direitos fundamentais.

A superação desse impasse no pensamento social contemporâneo somente poderá ser realizada se os direitos sociais forem considerados, tanto no que se refere a sua fundamentação, como na sua consagração constitucional, sob um paradigma diferente daquele encontrado na teoria liberal do direito e do estado. Para tanto, deve-se procurar estabelecer, assim como no caso dos direitos civis e políticos, uma fundamentação racional e ética, que possa justificar e legitimar o investimento público na proteção de dignidades humanas vulneráveis e fracas. Essa fundamentação no estado democrático de direito irá sedimentar-se através do procedimento democrático, implementado por indivíduos racionais, no exercício do discurso público no espaço da cidadania participativa. Um projeto público baseado na preservação de direitos e liberdades proclamados no corpo do estado liberal de direito realiza-se, em última análise, somente no estado democrático de direito, que se caracteriza como um sistema político e jurídico, legitimado pela integração teórica e objetiva dos direitos humanos.

Neste contexto, ganha relevância o debate entre constitucionalistas brasileiros sobre o conceito do "mínimo existencial". Inspirada na doutrina e na jurisprudência constitucional alemã, o "mínimo existencial” pretende atribuir ao indivíduo um direito subjetivo contra o Poder Público, que seria obrigado a garantir uma existência mínima digna a todos os cidadãos. Em nenhum momento, pode-se, entretanto, determinar em que reside esse "mínimo existencial", caindo-se, assim, no argumento do voluntarismo político, onde o mínimo para a vida humana fica a depender da vontade do governante.

Essa teoria, por sua imprecisão básica, tem servido de justificativa para interpretar a aplicação dos direitos sociais de forma restritiva, esvaziando a sua amplitude e magnitude. Isto significa que o princípio da dignidade humana, basilar no sistema constitucional, deixe de apresentar sua dimensão social e econômica. Para esses doutrinadores, a maximização dos direitos sociais implicaria no sacrifício do "mínimo existencial", pois, não havendo como 
assegura-los, o Estado seria impotente para garantir aquele mínimo, ainda que impreciso, e a ser definido pela vontade política, necessário para garantir uma sobrevivência condigna dos cidadãos.

Torna-se, assim, necessário que se responda a uma questão básica, se pretendemos atribuir aos direitos sociais o status de direito humano fundamental. Quais seriam os valores sociais básicos do estado democrático de direito? Enquanto no estado liberal-democrático esses valores eram a liberdade, a propriedade individual, a igualdade, a segurança jurídica e a representação política, no estado democrático de direito, não somente não se negam esses valores, mas procura-se dar aos mesmos, conteúdos materiais para torna-los mais efetivos. Por essa razão, torna-se cada vez mais problemática a garantia da liberdade, quando a sua implementação não vier acompanhada de condições existenciais que tornem possível o seu exercício real.

5. Direitos sociais e direitos fundamentais

A questão preliminar com que nos defrontamos, ao procurar estabelecer os direitos sociais como direito humano fundamental, reside no próprio conceito de direito fundamental, que tem duas principais acepções. Por um lado, o termo direito fundamental pode ser empregado para designar certos direitos que reconhecem e garantem a qualidade de pessoa ao ser humano. Este é o sentido filosófico da expressão, mas, também, e principalmente, na doutrina alemã contemporânea, tem sido empregada com o adjetivo "fundamental" Grundrecht- para referir-se aos direitos que, apesar de serem aqueles que o homem deve gozar por ser pessoa, só aparecem como fundamentais depois que o direito legislado os tenha reconhecido em sua positividade (Bidart e Herrendorf,1991:131). Entende-se, portanto, que existem e devem existir direitos humanos, antes e fora do direito positivo, mas não haveriam direitos fundamentais senão a partir da sua incorporação pelo direito positivo.

Os direitos fundamentais seriam diferenciados dos direitos humanos na medida em que fossem reconhecidos como tais pelas autoridades às quais se atribui o poder político de editar normas, tanto no interior dos Estados, quanto no plano internacional; são os direitos humanos positivados nas Constituições, nas leis, nos tratados internacionais. Essa noção, porém, revela-se radicalmente incompatível com o reconhecimento da existência de direitos 
humanos, pois a característica essencial destes consiste, justamente, no fato de valerem contra o Estado (Comparato, 1999:46). De fato, se admitirmos que o Estado nacional pode criar direitos humanos, e não apenas reconhecer a sua existência, é irrecusável admitir que o mesmo Estado também pode suprimi-los, ou alterar de tal maneira o seu conteúdo a ponto de torná-los irreconhecíveis ( Comparato, 1999: 47). Essa interpretação sobre a natureza dos direitos humanos explicita o argumento de que eles não têm um caráter universal, e eticamente obrigatórios, o que abre a possibilidade para a sua dependência da vontade do legislador. Não se trataria, assim, de atributos inerentes à condição humana, mas unicamente a determinada nacionalidade, regida pelo poder coercitivo de um Estado determinado.

A teoria dos Grundrechtes, portanto, exclui a característica da universalidade dos direitos humanos e consagra alguns desses direitos como fundamentais numa ordem jurídica específica e, finalmente, exclui dessa categoria os direitos sociais, ou seja, aqueles que dependem de uma atuação positiva do Estado. Todavia, dentro de uma interpretação ética dos direitos humanos, fundada em valores intrínsecos à racionalidade humana, deve-se compreender os direitos sociais como direitos essenciais e inafastáveis, por conseguinte fundamentais. A partir dessa eticidade dos direitos humanos, pode-se falar em direitos fundamentais sociais, quais sejam, aqueles que, em vez de serem direitos contra o Estado, se constituem em direitos através do Estado, exigindo do Poder Público certas prestações materiais, como a implementação de políticas sociais que facultem o gozo efetivo dos direitos constitucionalmente protegidos (Krell, 2001).

Os direitos humanos situam-se, em virtude de suas características morais, - o que torna essa categoria jurídica uma forma de contestação radical à teoria jurídica positivista para além e acima da organização estatal, deitando as suas raízes, em última instância, na consciência ética coletiva. A investigação sobre a natureza dos direitos humanos tem a ver com a busca dos modelos racionais e lógicos, que deitam as suas raízes na construção historicamente verificável de que esses direitos visam a proteção de bens e valores, que no seu todo constituem o cerne da dignidade humana e que foram sendo construídos no espaço público da sociedade democrática nos últimos dois séculos. O princípio constitucional da 
dignidade da pessoa humana ganha, assim, substância moral e jurídica, passando a integrar o sistema normativo, perdendo o seu caráter adjetivo, não mais sendo um simples ideal, pouco definido e dependente da vontade mutante do legislador.

Essa constatação exige que se situe a questão da fundamentação ética dos direitos sociais, para além da positivação jurídica. Trata-se, preliminarmente, de demonstrar que os direitos sociais têm as mesmas características de obrigatoriedade dos direitos humanos, participam também de sua natureza ética, tendo características de universalidade, a serem demonstradas através de uma fundamentação racional. A demonstração dessas características dos direitos sociais, como direitos humanos, pode ser elaborada em função da atribuição de qualidades que têm a ver com a dignidade humana. Deste modo poderemos comprovar em que medida os direitos sociais encontram-se no mesmo nível axiológico das liberdades individuais ou, então, dos desdobramentos dessas liberdades, no âmbito da distribuição dos bens. A atribuição de uma natureza ética aos direitos humanos e sociais constitucionais vem de encontro ao que pretendia o legislador constituinte, que ao legislar procurou expressar o entendimento ético que a sociedade tinha sobre o Direito e a organização do Estado. Atender, portanto, à vontade expressa pelo próprio constituinte, consiste, antes de tudo, em acatar as palavras empregadas no texto constitucional no seu sentido próprio e explícito. Isto para que o Direito expresso nas leis tenha um "efeito útil" (Mello, 1991:41), que no estado democrático do direito tem a ver com os objetivos estabelecidos no Preâmbulo da Constituição de 1988 e que perpassa todo o seu texto.

6. Etapas na fundamentação ética dos direitos sociais

Devemos examinar dois níveis de problemas, que se colocam no processo da fundamentação ética dos direitos sociais e que poderão servir como dados a serem levados em conta na nossa reflexão. Trata-se, no primeiro nível, de considerações de caráter mais abstrato e teórico, onde pontuamos o paradigma jurídico vigente nos dois últimos séculos; o segundo nível refere-se à questão das características objetivas do sistema jurídico, oriundo 
da concepção teórica. Procuraremos transitar por algumas falácias epistemológicas, que, quando resolvidas, permitem que se desvendem as razões pelas quais os direitos sociais, para alguns autores, não se encontram consagrados na categoria dos direitos humanos.

O primeiro momento da comprovação da natureza ética e universal dos direitos sociais pode ser identificado quando se considera o direito à igualdade, como critério aferidor daquela universalidade. $O$ segundo momento desdobra-se em conseqüência da leitura não reducionista da filosofia política kantiana, que se antepõe à leitura equivocada que tem servido, como veremos a seguir, de modelo teórico para justificar a posição que considera os direitos sociais como naturalmente contingentes.

6. Igualdade na liberdade como fundamento dos direitos sociais

Os direitos sociais, também chamados direitos de igualdade, correspondem à segunda geração dos direitos humanos. Surgiram em momento posterior aos direitos civis e políticos, direitos de liberdade, que integraram a primeira geração de direitos humanos. A primeira geração de direitos humanos começou a ser discutida no eclodir da Idade Moderna. A partir dos séculos XVI e XVII, a reação contra os excessos do absolutismo levou ao questionamento sobre os limites do poder do Estado. Os direitos da primeira geração direitos civis e políticos, cuja consolidação pacífica só se aperfeiçoou no século XVIII, com as primeiras Declarações de Direitos - são direitos de resistência e oposição perante o Estado. Dotados de subjetividade, são faculdades ou atributos inerentes à pessoa, oponíveis ao Estado e, que ao delimitarem o espaço intransponível da autonomia individual, estabelecem os limites a serem observados pelo poder público. Representaram

historicamente a positivação da superação do absolutismo através do estabelecimento do estado liberal de direito, que se instituiu em função e para preservar direitos do indivíduo face ao Estado.

O valor que inspirou o surgimento da primeira geração de direitos humanos foi a liberdade, mas é preciso ressalvar que a liberdade foi interpretada em sua acepção negativa. O conceito de liberdade, no sentido negativo, tal como compreendido pelos pensadores liberais, corresponde à ausência de restrição ou interferência. Liberdade negativa é a situação na qual o indivíduo tem a possibilidade de agir sem ser impedido, ou de não agir sem ser obrigado, por outros sujeitos. Nesse sentido, a liberdade consiste em fazer ou não fazer tudo 
que as leis, entendidas em sentido lato, e não apenas no sentido estritamente técnico-jurídico, permitem ou não proíbem fazer. Entretanto, essa liberdade que serve de base aos direitos da primeira geração pode sujeitar-se a algumas restrições, estabelecidas principalmente pela lei, no interesse da coesão, da justiça e de outros valores sociais, mesmo porque a garantia de uma liberdade estritamente negativa não é suficiente para permitir o adequado desenvolvimento dos atributos do ser humano.

Com efeito, a ordem liberal politicamente institucionalizada através dos direitos civis e políticos, assegurou o estabelecimento de um sistema social em torno da economia livre de mercado, economia esta que terminou por gerar um quadro de profundas e injustas desigualdades sociais, sob a égide de um Estado mais preocupado em representar os interesses dos detentores dos meios de produção do que em proteger os setores menos favorecidos ou mais fracos da sociedade. O Estado Liberal se comprometia apenas a garantir a liberdade dos cidadãos, e, por isso, pretendia apresentar-se como um instrumento neutro, afastado de qualquer implicação "material" de sua atividade e voltado para estabelecer claramente os seus limites com a sociedade civil. A satisfação dos interesses e das necessidades individuais, de acordo com a ideologia liberal, deveria ficar, assim, dependente do livre jogo dos agentes no mercado na sociedade civil, sem a interferência do Estado.

A idéia de um Estado de Polícia, isento e asséptico, mero garantidor da liberdade de iniciativa, não demorou em revelar-se uma ilusão. O Estado liberal, por trás de sua aparente neutralidade, na realidade estava a serviço de uma classe social, a classe dos detentores dos meios de produção, que necessitavam de um sistema jurídico que regulasse de forma igual os conflitos que ocorressem na sociedade civil e garantissem a atividade econômica da intervenção do Estado, para que assim pudesse ser realizado o reino da autonomia e da liberdade individual. Acontece que no seio da própria sociedade liberal ocorreram dissensões entre os detentores dos meios de produção, tornando-se uns mais fortes do que outros, em virtude, muitas vezes, da ação do poder público estatal, renegada ideologicamente, mas bem-vinda quando atendesse ao interesse privado sob as diferentes formas de incentivos e isenções fiscais. Ao mesmo tempo, os mecanismos de produção e distribuição de riqueza da economia liberal produziram prosperidade econômica crescente da sociedade como um todo, acompanhada de profundas desigualdades sociais. Essas 
desigualdades, que puniram durante décadas a massa de trabalhadores, serviram como condições sociais objetivas para o surgimento da categoria dos direitos sociais como direitos humanos, pois tinham a ver com a própria sobrevivência do indivíduo, prisioneiro das engrenagens da economia liberal. Os direitos sociais vieram a servir como o instrumento político e jurídico que serviu à democratização do sistema econômico e social da sociedade liberal.

Nesse contexto de desequilíbrio entre as condições de vida de diferentes classes sociais, foram, assim, formuladas as reivindicações sociais que serviram de fundamentos para a segunda geração dos direitos humanos, os direitos sociais, econômicos e culturais. Após a consagração dos limites ao poder do Estado no quadro do liberalismo, e depois que essas limitações contribuíram para a exclusão de grandes massas dos benefícios da sociedade industrial, tornou-se evidente a necessidade de democratização dessas liberdades conquistadas no contexto do Estado liberal, para defesa, inclusive, dos próprios direitos fundamentais desse sistema político.

Com a superação da ética liberal, o conceito de direitos fundamentais deixou de estar circunscrito ao status negativus libertatis, que vedava a interferência do Estado nas atividades da sociedade civil. A instituição dos direitos sociais supunha também a garantia do status positivus libertatis, que compreende o terreno das exigências, postulações e pretensões com que o indivíduo, dirigindo-se ao poder público, recebe em troca prestações. É, portanto, o status positivus que permite ao Estado construir socialmente as condições da liberdade concreta e efetiva. Deste modo, o Estado Social de Direito, substituindo o Estado Liberal, inclui no sistema de direitos fundamentais não só as liberdades clássicas, mas também os direitos econômicos, sociais e culturais. A satisfação de certas necessidades básicas e o acesso a certos bens fundamentais, para todos os membros da comunidade, passam a ser vistos como exigências éticas a que o Estado deve necessariamente responder.

A idéia de igualdade social, própria do Estado Social de Direito, não se identifica com a garantia de igualdade perante a lei, mera igualdade formal. Exige, ao contrário, um outro tipo de igualdade, material, que representa exatamente a superação da igualdade jurídica do liberalismo. Pelo princípio da igualdade material, assim desenvolvido, o Estado se obriga, mediante retificação na ordem social, a remover as injustiças encontradas na 
sociedade. Essa obrigação, entretanto, processa-se não através da pura e simples manifestação do voluntarismo político, mas como conseqüência da elaboração legislativa, que irá refletir as demandas dos excluídos dos benefícios da sociedade liberal. Antepõe-se, portanto, a sociedade liberal e a sociedade do estado democrático de direito, em virtude, precisamente, da natureza e função dos direitos civis e políticos num sistema jurídico que passou a ter nos direitos sociais a condição para a implementação dos objetivos últimos estabelecidos no texto consticuional. Deve-se enfatizar, aqui, que o surgimento dos direitos sociais não suprimiu nem apagou as conquistas referentes aos direitos civis e políticos. Ao contrário, o que se observa é que no século $\mathrm{XX}$, os direitos civis, políticos e sociais sofreram um processo de convergência, em virtude da maior democratização no exercício do poder, e passaram a constituir o núcleo da cidadania no Estado Democrático de Direito.

Outra questão que necessita ser analisada é a de que no Estado Democrático de Direito contemporâneo, os direitos fundamentais básicos estão cada vez mais dependentes da prestação de determinados serviços públicos, pois os direitos fundamentais de defesa somente podem ser eficazes quando protegem as condições materiais mínimas necessárias para a sua realização. Por exemplo, se o poder estatal deixa de desenvolver esforços para atender à população mais carente, que não tem recursos para pagar um plano privado de saúde, essas pessoas acabam sendo ameaçadas diretamente no seu direito à vida e à integridade física. Os direitos sociais, no quadro jurídico-político atual, concretizam a obrigação do Estado de controlar os riscos do problema da pobreza, que não podem ser atribuídos exclusivamente aos próprios indivíduos, restituindo um status mínimo de satisfação das necessidades pessoais. Os direitos sociais, econômicos e culturais constituem, junto com as liberdades civis e políticas, o acesso a essa dimensão maior da liberdade.

7. Justiça e dignidade da pessoa humana

Além dos valores da igualdade e da liberdade - conjugados na forma de igual direito à liberdade - os direitos sociais encontram fundamento ético na exigência de justiça, na medida em que são essenciais para a promoção da dignidade da pessoa humana, e indispensáveis para a consolidação do Estado Democrático de Direito. Esse regime, fundado sobre o princípio democrático, pretende assegurar a inclusão social, o que pressupõe 
participação popular e exercício dos direitos de cidadania. A cidadania, em seu conceito jurídico clássico, estabelece um vínculo jurídico entre o cidadão e o Estado. Esse vínculo, entretanto, no quadro do estado democrático de direito torna-se mais abrangente, pois cidadão é aquele que goza detém direitos civis (liberdades individuais) e políticos (participação política), mas também direitos sociais (trabalho, educação, habitação, saúde e prestações sociais em tempo de vulnerabilidade). O vínculo da cidadania, sob esse ponto de vista, materializa-se em duplo sentido. A cidadania permite que o indivíduo sinta-se partícipe da sociedade na medida em que esta sociedade se preocupe ativamente com sua sobrevivência, e com uma sobrevivência digna. Assim, verifica-se que a cidadania é uma relação de mão-dupla: dirige-se da comunidade para o cidadão, e também do cidadão para a comunidade. Portanto, só se pode exigir de um cidadão que assuma responsabilidades quando a comunidade política tiver demonstrado claramente que o reconhece como membro, inclusive, através da garantia de seus direitos sociais básicos. O reconhecimento de integração na comunidade depende, deste modo, não apenas da garantia dos direitos civis e políticos, mas também da participação nos direitos sociais indispensáveis para ter uma vida digna.

Os direitos sociais derivam, em última análise, do princípio constitucional da dignidade da pessoa humana, através de uma linha de eticidade. Assim, constata-se que não há distinção de grau entre os direitos sociais e os direitos individuais, pois ambos são elementos de um bem maior: a dignidade da pessoa humana, que tem duas face, conectadas, sobretudo, por sua fundamentação ética, universal, comum: a liberdade e a igualdade. É por essa razão que a eliminação das desigualdades continua sendo uma tarefa irrenunciável - em primeiro lugar, por razões de coerência entre um suposto ideal de igualdade e a própria idéia de democracia; em segundo lugar pela constatação de igual dignidade das pessoas, apesar das desigualdades físicas e psicológicas. Essa igualdade material é que irá garantir a cada indivíduo o gozo de renda mínima, moradia digna, emprego, assistência sanitária, educação fundamental e apoio em tempos de dificuldade.

8. A fundamentação ética dos direitos sociais

Revista Quaestio Iuris, vol.04, $\mathrm{n}^{\circ} 01$. ISSN 1516-0351 p.488-512 509 
Torna-se necessário que se estabeleçam os parâmetros teóricos dentro dos quais poderemos investigar a fundamentação ética dos direitos sociais, assim como foi extensamente elaborada a fundamentação ética dos direitos civis e políticos no alvorecer do estado liberal de direito. Os direitos relativos ao exercício das liberdades e do direito de propriedade, desde a formulação lockeana, que a considerava como uma das formalizações jurídicas do exercício da autonomia, são considerados como direitos universais e que se legitimam eticamente. Isto porque esses direitos expressam ou resultam do exercício da autonomia da pessoa humana. Assim, por exemplo, Locke situava a origem do direito de propriedade (Segundo Tratado do Governo Civil, V) no exercício pelo homem de atos que visam retirar, através do trabalho, da propriedade comum, parte que passariam a legitimamente integrar a propriedade individual. A lei de moralidade, por sua vez, na primeira formulação kantiana, expressa (Fundamentação da Metafísica dos Costumes) a idéia de que se encontra implícito no exercício das liberdades, através da manifestação das vontades autônomas, e estabelecimento de limites comuns para o seu exercício. No âmbito das liberdades, por referirem-se num primeiro momento a relações intersubjetivas, a natureza ética das mesmas torna-se evidente. O mesmo não ocorre, entretanto, com os direitos sociais, que são por natureza direitos públicos, a serem realizados coletivamente. O modelo teórico do qual podemos nos socorrer para examinar a fundamentação ética dos direitos sociais é o kantiano. Torna-se, no entanto, oportuno esclarecer duas questões preliminares: primeiro,quais as consequiências práticas da atribuição do caráter ético aos direitos sociais; e segundo, por quê Kant ?

Esses dois questionamentos podem ser, conjuntamente, respondidos. A leitura de Kant tem sido, a meu ver, realizada de modo reducionista, aceitando-se de forma a-crítica a afirmação de que o filósofo alemão erige a lei de moralidade como sendo, principalmente, individual, aplicada exclusivamente aos indivíduos. A contrario sensu, alguns autores (Höffe, 1993; Cortina, 1998) consideram que se pode, sem violação do texto kantiano, afirmar-se que, partindo-se da segunda formulação do imperativo da moralidade - “ seres racionais estão pois todos submetidos a esta lei que manda que cada um deles jamais se trate a si mesmo ou aos outros simplesmente como meios, mas sempre simultaneamente como fins"( Kant, 1960:76)- podemos evidenciar como a fundamentação ética kantiana aponta para a natureza social do ser humano. Em conseqüência, argumenta Höffe, podemos retirar das 
entrelinhas da obra kantiana um outro tipo de imperativo, o imperativo jurídico categórico. Encontramos, assim, implícito em Kant - que nunca empregou diretamente a expressão "imperativo jurídico categórico" - uma abertura metodológica que nos permitirá desenvolver a idéia de que os direitos sociais têm caráter de universalidade obrigatória, isso por serem direitos que se encontram nas origens da sociedade humana, representando a dimensão da pessoa como bios politikòn.

Bibliografia

Adela Cortina, Ciudadanos del Mundo: hacia une teoria de la ciudadania, Madrid, Alianza Editorial, 1998

Andréas Krell,- “ Controle judicial dos serviços públicos básicos na base dos direitos fundamentais sociais", em A Constituição Concretizada, Porto Alegre, Livraria do Advogado Editora, 2000

-Direitos Sociais e Controle Judicial no Brasil e na Alemanha, Porto Alegre, Sérgio Antônio Fabris Editor, 2002

C. B. Macpherson, The Political Theory of Possessive Individualism, London, Oxford University Press, 1962

Celso Albuquerque de Mello, Direitos Humanos e Conflitos Armados, Rio de Janeiro, Editora renovar, 1991

Celso Fernandes Campilongo, "O trabalhador e o direito à saúde: a eficácia dos direitos sociais e o discurso neoliberal", em Direito, cidadania e justiça: ensaios sobre lógica, interpretação, teoria sociológica e filosofia jurídica, coord. Beatriz di Giorgi, Celso Fernandes Campilongo e Flávia Piovesan, São Paulo, Revista dos Tribunais, 1995.

Fabio Konder Comparato, Afirmação Histórica dos Direitos Humanos, São Paulo, Saraiva, 1999

German J. Bidart e Daniel E. Herrendorf, Principios de Derechos Humanos y Garantias, Buenos Aires, Ediar, 1991

Immanuel Kant, Fundamentação da Metafísica dos Costumes, Lisboa, Edições 70, 1960 


\section{Quaestio Iuris}

Ingo Wolfgang Sarlet, A Eficácia dos Direitos Fundamentais, Porto Alegre, Livraria dos Advogados Editora, 2001

John Locke, Two Treatises of Government, New York and Toronto, New American Library, 1965

Lênio Streck, Jurisdição Constitucional e Hermenêutica, Porto Alegre, Livraria do Advogado Editora, 2002

Luiz Roberto Barroso, O Direito Constitucional e a efetividade de suas normas, Rio de Janeiro, Renovar, 1999.

Martinez de Bringas Globalización y Derechos Humanos, Bilbao, Universidad de Deusto, 2001

Max Weber, Economia y Sociedad, México, Fondo de Cultura Econômica, 1944

Norberto Bobbio, A Era dos Direitos, Rio de Janeiro, Campus, 1992

Otfried Höffe, Príncipes du Droit, Paris, Cerf, 1993.

Ricardo Lobo Torres, “A cidadania multidimensional na era dos direitos”, em Teoria dos Direitos Fundamentais, org. Ricardo Lobo Torres, Rio de Janeiro, Renovar, 1999

T. H. Marshall, Cidadania, Classe Social e Status, Rio de Janeiro, Zahar Editores, 1967 